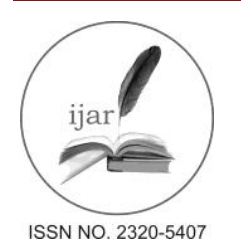

\author{
Journal homepage: http://www.journalijar.com

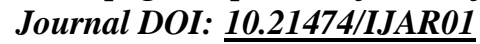

INTERNATIONAL JOURNAL

OF ADVANCED RESEARCH

RESEARCH ARTICLE

\title{
GC-MS ANALYSIS AND BIOLOGICAL ACTIVITY OF FIXED OIL FROM SUDANESE CAJANUS CAJAN (L.) (LEGUMINOSEAE) SEEDS.
}

\author{
Abdel Karim. M. ${ }^{{ }^{*}}$, Zohor. M. ${ }^{1}$, Inas. O. ${ }^{2}$ and EL-Hafez. M. ${ }^{3}$. \\ 1. Sudan University of Science and Technology, Faculty of Science. \\ 2. University of Bahri, College of Applied and Industrial Science,Dept. of Chemistry. \\ 3. Gezira University, Faculty of Education.
}

\section{Manuscript Info}

Manuscript History:

Received: 18 February 2016

Final Accepted: 19 March 2016

Published Online: April 2016

Key words:

Cajanus cajan, Fixed oil ,GC-MS,

Biological activity.

*Corresponding Author

Abdel Karim. M.

\begin{abstract}
The present study was designed to identify the constituents of the fixed oil from seeds of Sudanese Cajanus cajan (L), and to evaluate its antimicrobial activity. GC- MS analysis of the fixed oil revealed the presence of 9,12octadecadienoic acid (35.28\%), hexadecanoic acid (19.74\%), 9-octadecenoic acid $(19.14 \%)$, methyl stearate $(6.71 \%)$ beside other minor constituents. In cup plate agar diffusion assay, the oil was screened for antimicrobial activity against six standard human pathogens and promising results were obtained.
\end{abstract}

\section{Introduction:-}

Leguminous plants belong to the family Fabaceae (Leguminosae). The fruits of these plants are called legumes . Legume seed and foliage have comparatively higher protein content than non legume materials, probably due to the additional nitrogen that legume received from nitrogen fixation symbiosis( David, 2014).

Cajanus cajan (L) known in Sudan (Aladassia) is one of the major grain legume crops grown in semi- arid tropics. It is valued both as food and fodder(Rama et.al.2013) . Pigeon pea (Cajanus cajan L.) probably evolved in South Asia and appeared about 2000 B.C . in West Africa which is considered as a second major center of origin( Van Den Beldt, 1988). The slave trade took it to the Western Indies, where it is used as bird feed and this led to the name "Pigeon Pea" in 1692. Pigeon Pea (Cajanus cajan L.) is a leguminous plant (Van Der Maesen,1986) .

Pigeon Pea is a rich source of protein, carbohydrates and certain minerals. The protein content of commonly grown pigeon pea cultivars range between $17.9-24.3 \mathrm{~g} / 100 \mathrm{ml} \mathrm{g}$ for whole grain samples( Salunkhe et.al.,1985) . The pigeon pea plant as whole has been found useful. It is used for food and fuel . It is most widely eaten in the form of seeds ; it contains protein with amino acids profile similar to that of soybean (Singh et.al.,1990).Pigeon pea seeds contain about 57.3-58.7\% carbohydrate, $1.2-8.1$ crude fiber and 0.6 - 3.8\% lipids( Singh , 1977).

Cajanus cajan is an erect, branched, hairy shrub, 1-2 meters high. Leaves are oblong-lanceolate to oblanceolate with three leaflets. Flowers are yellow, in sparse peduncled racemes, about $1.5-\mathrm{cm}$ long.

It has been cultivated in ancient Egypt, Africa and Asia since prehistoric times, and was later introduced to America. Now it acclimatizes in several tropical countries. The major producer is India contributing about $90 \%$ of world production. Its altitude range is $1250 \mathrm{~m}$ in Hawaii, $0-3000 \mathrm{~m}$ in India and Columbia. It is essentially a plant of the semi-dry lowlands but has wide adaptability ( Duke ,2004).

Pod is hairy, 4-7 cm long, $1 \mathrm{~cm}$ wide, containing two to seven seeds. The leaves are used for rearing silkworms while green pods are used as a vegetable.Also leaves and tops are used as fodder( Ambasta ,2004). Recently this 
species has also been explored for the treatment of an array of human diseases including: an ischemic necrosis of the caput femoris, bed-sore and wound healing. Phytochemical investigations have revealed the presence of globulins, cajanin and concajanin (Ambasta ,2004). Cajanus cajan is used traditionally as a sedative(Ahsan and Islam,2009a) and for treating, sores, skin irritations, hepatitis, measles, jaundice and dysentery . It is also employed for expelling bladder stones and stabilizing menstrual period( Yuan-gang ,2010).

Alcoholic extracts of the aerial parts of $C$. cajan were evaluated for anthelmintic properties(Pal et.al.,2007; Pal et.al.2008). This property was supposed to be due to the presence of phenolics (flavanoids and tannins) which are reported to have good anthelmintic property(Singh et.al. 2010).In a study, the glycemic profile of the aqueous extract of $C$. cajan leaves in streptozocin-induced Type 2 diabetic rats was evaluated. This extract showed significant increment in fasting blood glucose levels of normal rats. The study of leaves was taken into consideration on the basis of earlier reported hypoglycemic activity of $C$. cajan seeds. However, the results observed for leaves were found to be just opposite and therefore leaves may be useful in controlling hypoglycemia occasionally caused due to excess of insulin and other hypoglycemic drugs (Jaiswal et.al.,8008).In animal model study, the methanolic extract of $C$. cajan was investigated for hepatoprotective activity against carbon tetrachloride - induced liver damage. It was found that the extract exhibited a moderate protective effect by lowering the serum levels of alanine aminotransferase (ALT) or serum glutamate pyruvate transaminase (SGPT), aspartate aminotransferase (AST) or serum glutamate oxaloacetate transaminase (SGOT), and cholesterol to a significant extent( Ahsan and Islam,2009b). Aqueous methanol fraction of the leaf extract also prevented alcohol- induced rat liver damage.

Cajanol, an isoflavanone from C. cajan roots is an important phytoalexin. The anticancer activity of cajanol towards MCF-7 human breast cancer cells was investigated. Cajanol inhibited the growth of MCF-7 cells in a time- and dose-dependent manner. Cajanol arrested the cell cycle in the G2/M phase and induced apoptosis via a reactive oxygen species (ROS) -mediated mitochondria-dependent pathway( Luo et.al. ,2010)

\section{Materials and Methods.}

\section{Plant material:-}

Seeds of Cajanus cajan were purchased from the local market-Khartoum. The plant was kindly authenticated by Institute of Aromatic and Medicinal Plants-Khartoum,Sudan.

\section{Instruments:-}

A Shimadzo GC-MS-QP2010 Ultra instrument with a RTX-5MS column (30m,length ; $0.25 \mathrm{~mm}$ diameter ; $0.25 \mu \mathrm{m}$, thickness)was used.

\section{Test organisms:-}

Cajanus cajan oil was screened for antibacterial and antifungal activities using the standard microorganisms shown in Table(1).

Table 1: Test organisms.

\begin{tabular}{|l|l|l|}
\hline Ser. No & Microorganism & Type \\
\hline 1 & Bacillus subtilis & G+ve \\
\hline 2 & Staphylococcus aureus & G+ve \\
\hline 3 & Pseudomonas aeroginosa & G-ve \\
\hline 4 & Escherichia coli & G-ve \\
\hline 5 & Aspergillus niger & fungi \\
\hline 6 & Candida albicans & fungi \\
\hline
\end{tabular}

\section{Methods:-}

\section{Extraction of oil from seeds of Cajanus cajan}

Powdered seeds of Cajanus cajan (200g) were exhaustively extracted with n-hexane (soxhlet). The solvent was removed under reduced pressure and the oil was kept in the fridge at $4^{\circ} \mathrm{C}$ for further manipulation.

\section{Esterification of oil:-}

A Methanolic solution of sodium hydroxide was prepared by dissolving ( $2 \mathrm{~g}$ ) of sodium hydroxide in $100 \mathrm{ml}$ methanol.A stock solution of methanolic sulphuric acid was prepared by mixing ( $1 \mathrm{ml}$ )of concentrated sulphuric acid with $(99 \mathrm{ml})$ methanol. 
The oil $(2 \mathrm{ml})$ was placed in a test tube and $7 \mathrm{ml}$ of alcoholic sodium hydroxide were added followed by $7 \mathrm{ml}$ of alcoholic sulphuric acid.The tube was stoppered and shaked vigorously for five minutes and then left overnight.(2ml) of supersaturated sodium chloride were added, then $(2 \mathrm{ml})$ of normal hexane were added and the tube was vigorously

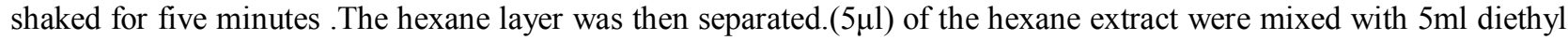
ether. The solution was filtered and the filtrate $(1 \mu \mathrm{l})$ was injected in the GC-MS vial.

\section{GC-MS analysis:-}

Cajanus cajan fixed oil was analyzed by gas chromatography - mass spectrometry.A Shimadzo GC-MS-QP2010 Ultra instrument with a RTX-5MS column (30m,length ; $0.25 \mathrm{~mm}$ diameter ; $0.25 \mu \mathrm{m}$, thickness)was used.Helium (purity; $99.99 \%$ ) was used as carrier gas.Oven temperature program is given in Table 2, while other chromatographic conditions are depicted in Table 3.

Table 2: Oven temperature program.

\begin{tabular}{|l|l|l|}
\hline Rate & Temperature $\left({ }^{\circ} \mathrm{C}\right)$ & Hold Time $\left(\right.$ min. $\left.^{-1}\right)$ \\
\hline- & 150.0 & 1.00 \\
4.00 & 300.0 & 0.00 \\
\hline
\end{tabular}

Table 3: Chromatographic conditions.

\begin{tabular}{|ll|}
\hline Column oven temperature & $150.0^{\circ} \mathrm{C}$ \\
Injection temperature & $300.0^{\circ} \mathrm{C}$ \\
Injection mode & Split \\
Flow control mode & Linear velocity \\
Pressure & $139.3 \mathrm{KPa}$ \\
Total flow & $50.0 \mathrm{ml} / \mathrm{min}$ \\
Column flow & $1.54 \mathrm{ml} / \mathrm{sec}$. \\
Linear velocity & $47.2 \mathrm{~cm} / \mathrm{sec}$. \\
Purge flow & $3.0 \mathrm{ml} / \mathrm{min}$. \\
Spilt ratio & -1.0 \\
\hline
\end{tabular}

\section{Antimicrobial assay:-}

Preparation of bacterial suspensions:-

One $\mathrm{ml}$ aliquots of 24 hours broth culture of the test organisms were aseptically distributed onto nutrient agar slopes and incubated at $37^{\circ} \mathrm{C}$ for 24 hours.

The bacterial growth was harvested and washed off with sterile normal saline, and finally suspended in $100 \mathrm{ml}$ of normal saline to produce a suspension containing about $10^{8}-10^{9}$ colony forming units per ml.The suspension was stored in the refrigerator at $4^{\circ} \mathrm{C}$ until used. The average number of viable organism per $\mathrm{ml}$ of the stock suspension was determined by means of the surface viable counting technique.

Serial dilutions of the stock suspension were made in sterile normal saline in tubes and one drop volumes (0.02 ml) of the appropriate dilutions were transferred by adjustable volume micropipette onto the surface of dried nutrient agar plates. The plates were allowed to stand for two hours at room temperature for the drop to dry, and then incubated at $37^{\circ} \mathrm{C}$ for 24 hours.

\section{Preparation of fungal suspensions:-}

Fungal cultures were maintained on dextrose agar incubated at $25^{\circ} \mathrm{C}$ for four days. The fungal growth was harvested and washed with sterile normal saline, and the suspension was stored in the refrigerator until used.

\section{Testing for antibacterial activity:-}

The cup-plate agar diffusion method was adopted, with some minor modifications, to assess the antibacterial activity. ( $2 \mathrm{ml}$ ) of the standardized bacterial stock suspension were mixed with $200 \mathrm{ml}$ of sterile molten nutrient agar which was maintained at $45^{\circ} \mathrm{C}$ in a water bath. $(20 \mathrm{ml})$ Aliquots of the incubated nutrient agar were distributed into sterile Petri dishes. The agar was left to settle and in each of these plates which were divided into two halves, two cups in each half (10 $\mathrm{mm}$ in diameter) were cut using sterile cork borer (No 4), each one of the halves was designed for one of the test solutions. Separate Petri dishes were designed for standard antibacterial chemotherapeutics(ampicillin and gentamycin). 
The agar discs were removed, alternate cups were filled with $0.1 \mathrm{ml}$ samples of each test solution using adjustable volume microtiter pipette and allowed to diffuse at room temperature for two hours. The plates were then incubated in the upright position at $37^{\circ} \mathrm{C}$ for 24 hours.

The above procedure was repeated for different concentrations of the test solutions and the standard chemotherapeutics. After incubation, the diameters of the resultant growth inhibition zones were measured in triplicates and averaged.

\section{Results and Discussion:-}

The GC-MS analysis of Cajanus cajan fixed oil:-

GC-MS analysis of Cajanus cajan oil was conducted and the identification of the constituents was initially accomplished by comparison with the MS library (NIST) and further confirmed by interpreting the observed fragmentation pattern. Comparison of the mass spectra with the database on MS library revealed about 90-95\% match.

\section{Constituents of oil:-}

The GC-MS spectrum of the studied oil revealed the presence of 48 components(Table 4).The typical total ion chromatograms(TIC) is depicted in Fig.1.

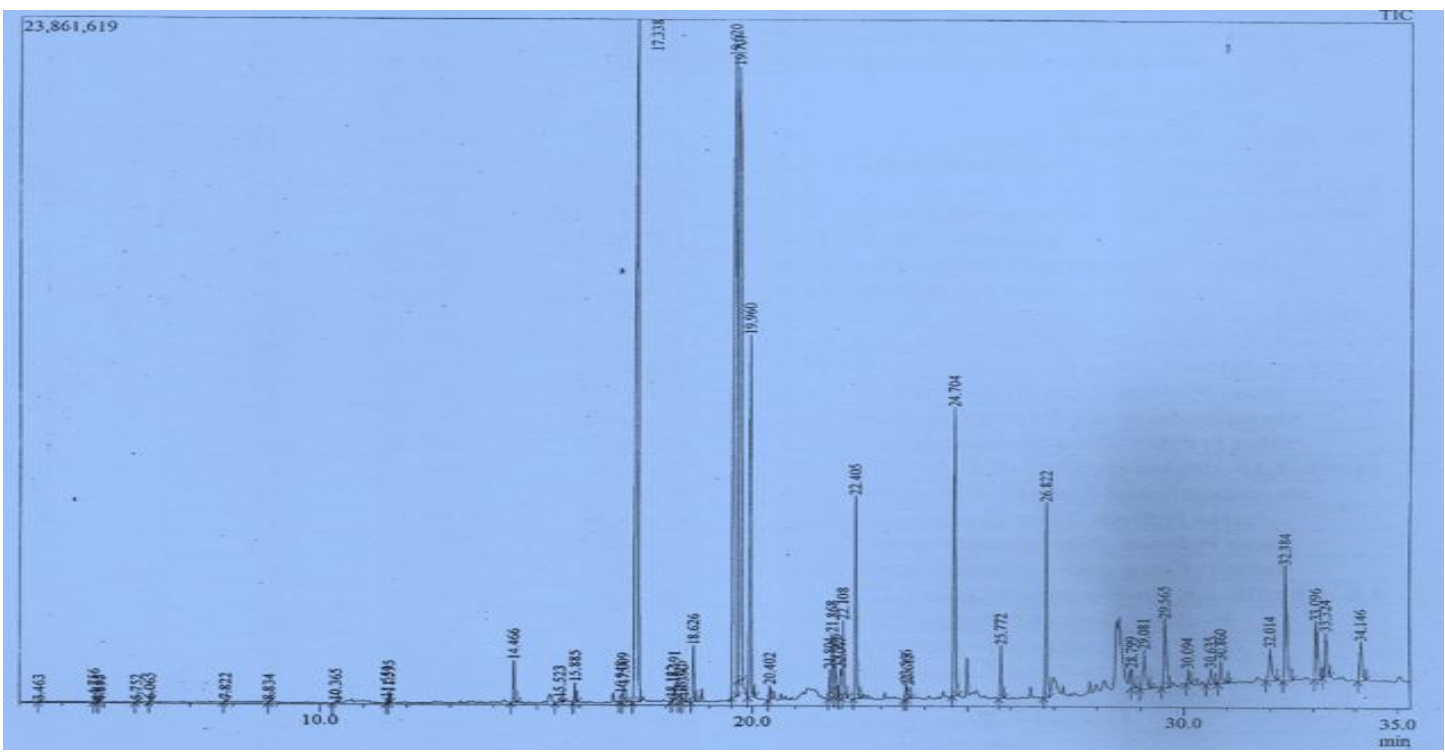

Fig. 1: Total ion chromatograms-Cajanus cajan oil. 
Table 4: Contituents of Cajanus cajan oil.

\begin{tabular}{|c|c|c|c|c|}
\hline \multicolumn{5}{|c|}{ Peak Report TIC } \\
\hline Peak\# & R.Time & Area & Area $\%$ & Name \\
\hline 1 & 3.463 & 45181 & 0.01 & Hexanoic acid, methyl ester \\
\hline 2 & 4.756 & 378117 & 0.07 & 1-Hexanol, 2-ethyl- \\
\hline 3 & 4.835 & 28965 & 0.01 & D-Limonene \\
\hline 4 & 4.895 & 38131 & 0.01 & Eucalyptol \\
\hline 5 & 5.752 & 67374 & 0.01 & Benzoic acid, methyl ester \\
\hline 6 & 6.065 & 130506 & 0.02 & Octanoic acid, methyl ester \\
\hline 7 & 7.822 & 148640 & 0.03 & Propanal, 2-methyl-3-phenyl- \\
\hline 8 & 8.834 & 107545 & 0.02 & Decanoic acid, methyl ester \\
\hline 9 & 10.365 & 168379 & 0.03 & Nonanoic acid, 9-oxo-, methyl ester \\
\hline 10 & 11.551 & 288422 & 0.05 & Butylated Hydroxytoluene \\
\hline 11 & 11.595 & 574204 & 0.11 & Dodecanoic acid, methyl ester \\
\hline 12 & 14.466 & 2678501 & 0.51 & Methyl tetradecanoate \\
\hline 13 & 15.523 & 365995 & 0.07 & 5-Octadecenoic acid, methyl ester \\
\hline 14 & 15.885 & 1339792 & 0.25 & 6-Octadecanoic acid,methyl ester \\
\hline 15 & 16.948 & 724529 & 0.14 & 7-Hexadecenoic acid, methyl ester, (Z)- \\
\hline 16 & 17.009 & 1425287 & 0.27 & 9-Hexadecenoic acid, methyl ester, (Z)- \\
\hline 17 & 17.338 & 103704422 & 19.74 & Hexadecanoic acid, methyl ester \\
\hline 18 & 18.132 & 255757 & 0.05 & Heptadecanoic acid, methyl ester \\
\hline 19 & 18.191 & 1092231 & 0.21 & Hexadecanoic acid, ethyl ester \\
\hline 20 & 18.326 & 619157 & 0.12 & Methyl 5,12-octadecadienoate \\
\hline 21 & 18.390 & 352836 & 0.07 & cis-10-Heptadecenoic acid, methyl este \\
\hline 22 & 18.626 & 4264521 & 0.81 & Heptadecanoic acid, methyl ester \\
\hline 23 & 19.620 & 114698256 & 21.83 & 9,12-Octadecadienoic acid $(Z, Z)$-, meth \\
\hline 24 & 19.707 & 100575541 & 19.14 & 9-Octadecenoic acid (Z)-, methyl ester \\
\hline 25 & 19.960 & 35281712 & 6.71 & Methyl stearate \\
\hline 26 & 20.402 & 1040252 & 0.20 & n-Propyl 9,12-octadecadienoate \\
\hline 27 & 21.804 & 2389371 & 0.45 & Methyl 5,13-docosadienoate \\
\hline 28 & 21.868 & 4351750 & 0.83 & $6,9,12,15$-Docosatetraenoic acid, methy \\
\hline 29 & 21.936 & 2285322 & 0.43 & $9,12,15$-Octadecatrienoic acid, methyl \\
\hline 30 & 22.047 & 2746069 & 0.52 & Oxiraneoctanoic acid, 3-octyl-, methyl \\
\hline 31 & 22.108 & 7199025 & 1.37 & 11-Eicosenoic acid, methyl ester \\
\hline 32 & 22.405 & 17963125 & 3.42 & Methyl 18-methylnonadecanoate \\
\hline 33 & 23.566 & 1348350 & 0.26 & Heneicosanoic acid, methyl ester \\
\hline 34 & 23.615 & 951870 & 0.18 & Phenol, 2,2'-methylenebis [6-(1,1-dimet \\
\hline 35 & 24.704 & 28773655 & 5.48 & Methyl 20-methyl-heneicosanoate \\
\hline 36 & 25.772 & 4439533 & 0.84 & Tricosanoic acid, methyl ester \\
\hline 37 & 26.822 & 18338029 & 3.49 & Tetracosanoic acid, methyl ester \\
\hline 38 & 28.799 & 1746727 & 0.33 & Hexacosanoic acid, methyl ester \\
\hline 39 & 29.081 & 6234786 & 1.19 & 2H-1-Benzopyran-6-ol, 3,4-dihydro-2,8 \\
\hline 40 & 29.565 & 10051199 & 1.91 & Stigmast-8(14)-en-3.beta.-ol \\
\hline 41 & 30.094 & 1214910 & 0.23 & .gamma.-Tocopherol \\
\hline 42 & 30.635 & 2208114 & 0.42 & Stigmast-5-en-3-ol, oleate \\
\hline 43 & 30.860 & 3014340 & 0.57 & Cholest-5-en-3-ol, (3.alpha.)- \\
\hline 44 & 32.014 & 5335788 & 1.02 & .gamma.-Ergostenol \\
\hline 45 & 32.384 & 14984963 & 2.85 & Stigmasterol \\
\hline 46 & 33.096 & 7968014 & 1.52 & Stigmast-7-en-3-ol, (3.beta.,5.alpha.,24 \\
\hline 47 & 33.324 & 5655388 & 1.08 & Fucosterol \\
\hline \multirow{2}{*}{48} & 34.146 & 5854661 & 1.11 & 9,19-Cyclolanost-24-en-3-ol, (3.beta.)- \\
\hline & & 525449242 & 100.00 & $x^{2}$ \\
\hline
\end{tabular}


The most important constituents are discussed below:

9-Octadecenoic acid methyl ester(19.14\%):-

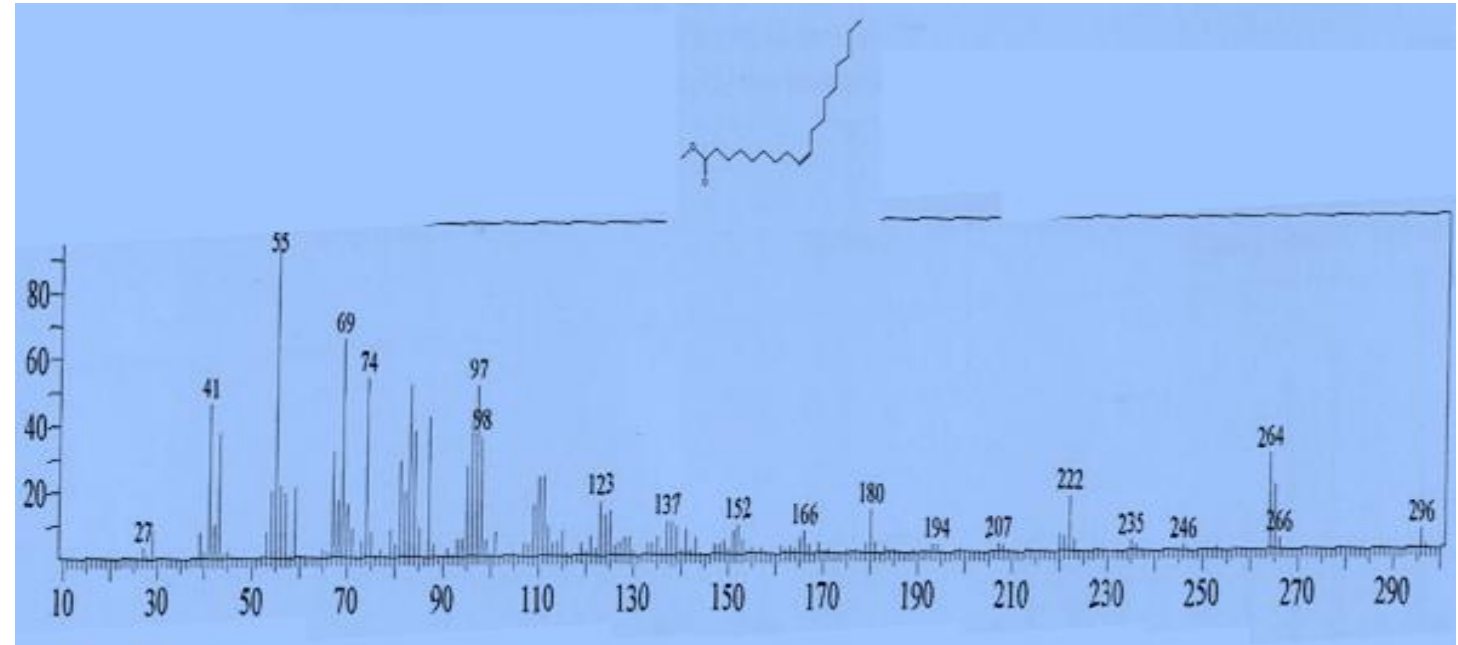

Fig. 2: Mass spectrum of 9-octadecenoic acid methyl ester.

The EI mass spectrum of 9-octadecenoic acid methyl ester is shown in Fig. 2.The peak at $\mathrm{m} / \mathrm{z} 296$, which appeared at R.T. 19.707 in total ion chromatogram, corresponds to $\mathrm{M}^{+}\left[\mathrm{C}_{19} \mathrm{H}_{36} \mathrm{O}_{2}\right]^{+}$. The peak at $\mathrm{m} / \mathrm{z} 266$ is due to loss of a methoxyl function.

\section{9,12-Octadecadienoic acid methyl ester (21.83\%):-}

The EI mass spectrum of 9,12-octadecadienoic acid methyl ester is shown in Fig.3 .The peak at $\mathrm{m} / \mathrm{z} 294$, which appeared at R.T. 19.620 in total ion chromatogram, corresponds to $\mathrm{M}^{+}\left[\mathrm{C}_{19} \mathrm{H}_{34} \mathrm{O}_{2}\right]^{+}$. The peak at $\mathrm{m} / \mathrm{z} 263$ corresponds to loss of a methoxyl function.

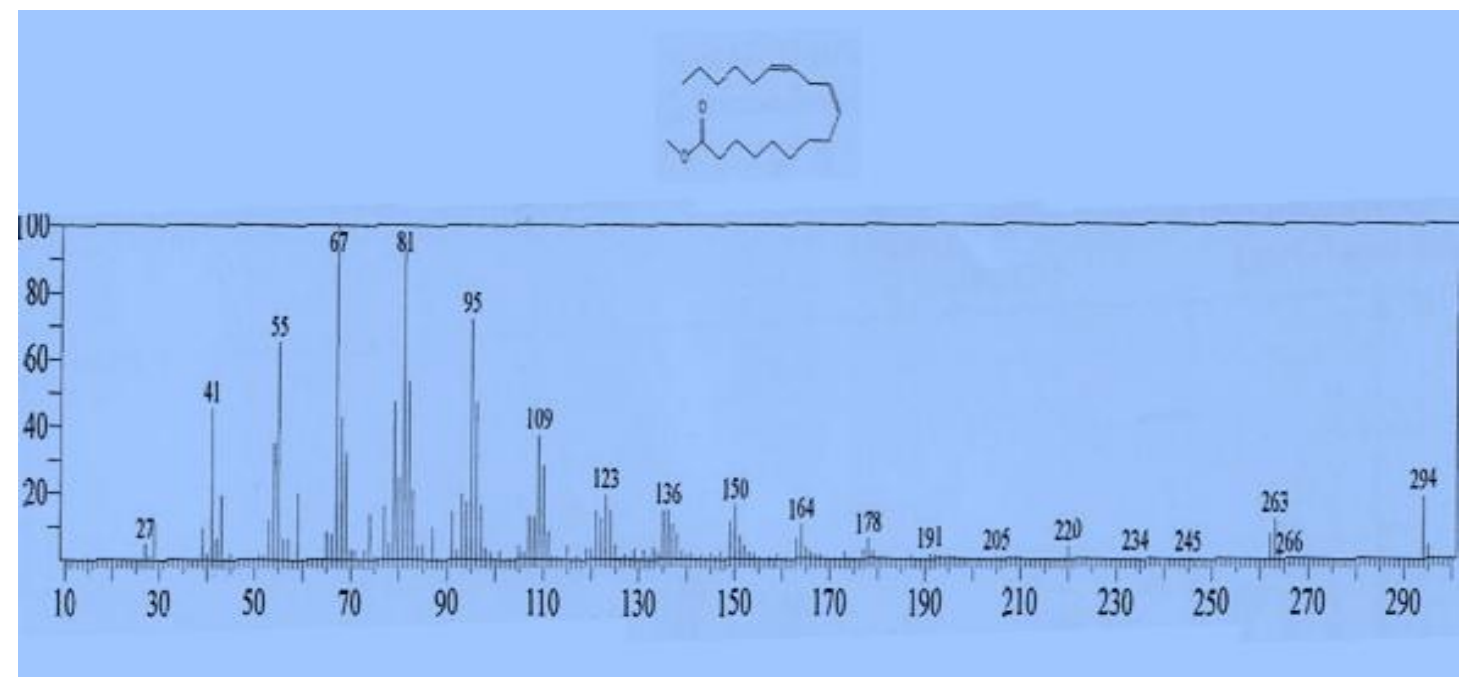

Fig. 3: Mass spectrum of 9,12-octadecadienoic acid methyl ester. 


\section{Hexadecanoic acid methyl ester(19.74\%):-}

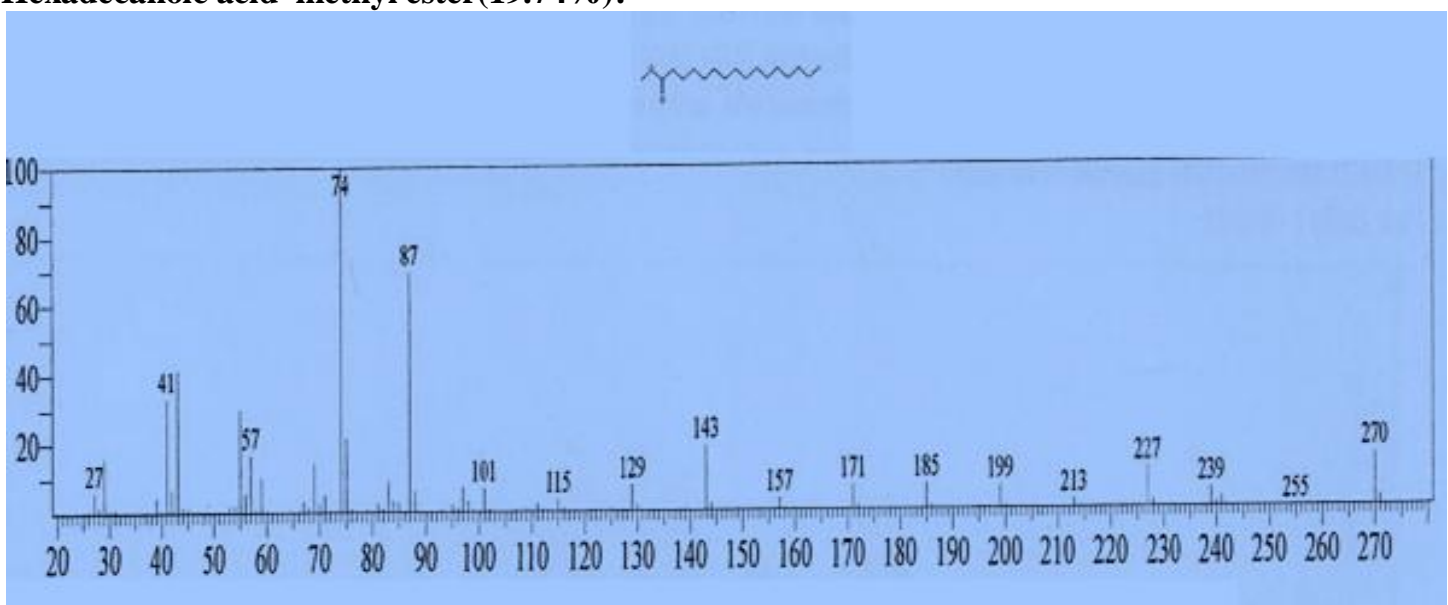

Fig. 4: Mass spectrum of hexadecanoic acid methyl ester.

The EI mass spectrum of hexadecanoic acid methyl ester is shown in Fig. 4. The peak at $\mathrm{m} / \mathrm{z} 270$, which appeared at R.T. 17.338 in total ion chromatogram, corresponds to $\mathrm{M}^{+}\left[\mathrm{C}_{17} \mathrm{H}_{34} \mathrm{O}_{2}\right]^{+}$. The peak at $\mathrm{m} / \mathrm{z} 239$ is due to loss of a methoxyl function.

\section{Methyl stearate(6.71\%):-}

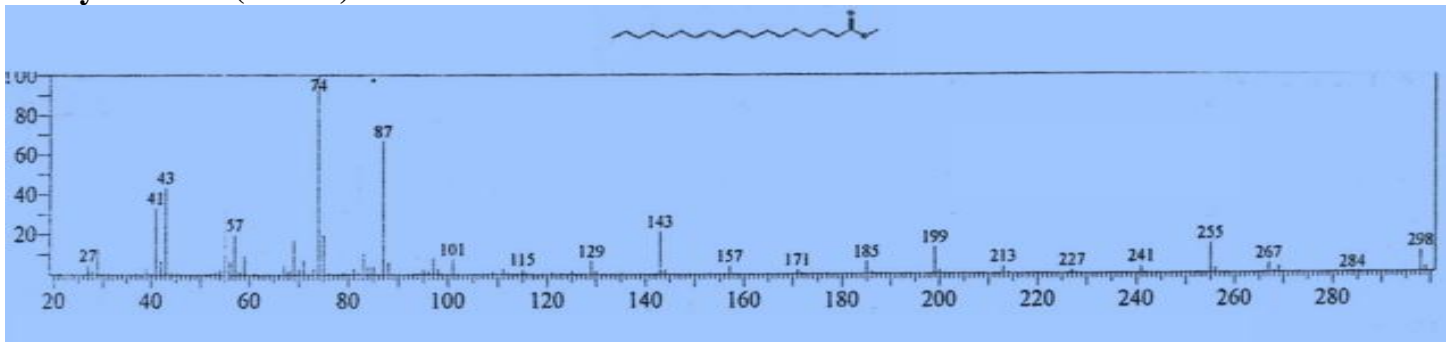

Fig. 5: Mass spectrum of methyl stearate.

The EI mass spectrum of methyl stearate is shown in Fig. 5.The peak at $\mathrm{m} / \mathrm{z} 298$, which appeared at R.T. 19.960 in total ion chromatogram, corresponds to $\mathrm{M}^{+}\left[\mathrm{C}_{19} \mathrm{H}_{38} \mathrm{O}_{2}\right]^{+}$. The peak at $\mathrm{m} / \mathrm{z} 267$ corresponds to loss of a methoxyl function.

\section{Tetracosanoic acid methyl ester(3.45\%):-}

The EI mass spectrum of Tetracosanoic acid methyl ester is shown in Fig. 6. The peak at m/z382, which appeared at R.T. 26.822 in total ion chromatogram, corresponds to $\mathrm{M}^{+}\left[\mathrm{C}_{25} \mathrm{H}_{50} \mathrm{O}_{2}\right]^{+}$. The peak at $\mathrm{m} / \mathrm{z} 351$ corresponds to loss of a methoxyl function.

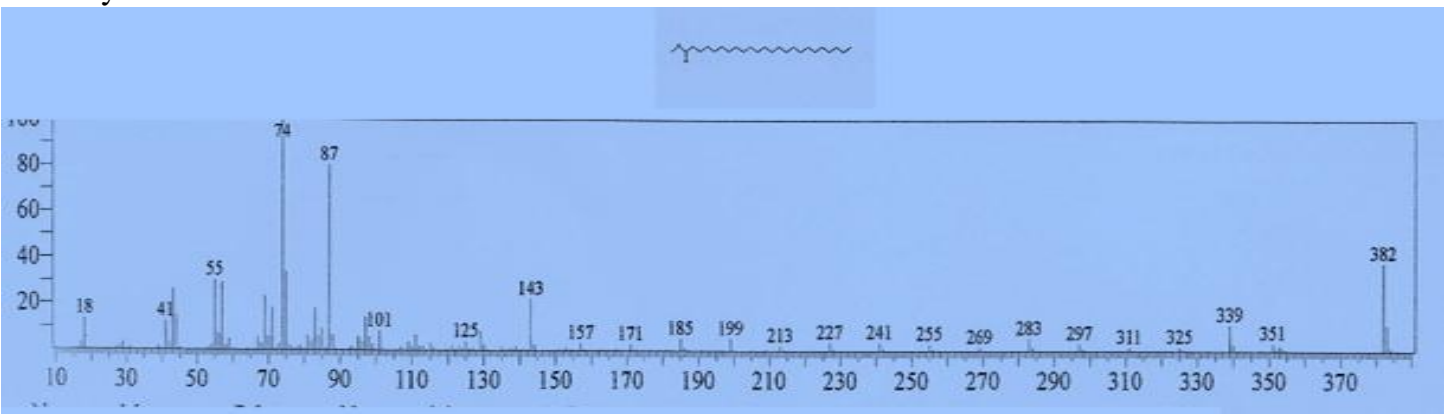

Fig. 6: Mass spectrum of Tetracosanoic acid methyl ester 


\section{Antibacterial activity:-}

The oil was screened for antimicrobial activity against six standard organisms. The average of the diameters of the growth of inhibition zones are depicted in Table (5). The results were interpreted in terms of the commonly used terms (<9mm: inative;9-12mm:partially active; $13-18 \mathrm{~mm}$ : active; $>18 \mathrm{~mm}$ :very active) .Tables (6) and (7) represent the antimicrobial activity of standard antibacterial and antifungal chemotherapeutic agents against standard bacteria and fungi respectively.

Table 5 : Antibacterial activity of Cajanus cajan oil :M.D.I.Z (mm).

\begin{tabular}{|l|l|l|l|l|l|l|l|}
\hline & Conc. $(\mathrm{mg} / \mathrm{ml})$ & Ec & Ps & Sa & Bs & Ca & An \\
\hline oil & 100 & 14 & 15 & 16 & 13 & 15 & 16 \\
\hline
\end{tabular}

Table 6 : Antibacterial activity of standard chemotherapeutic agents :M.D.I.Z (mm)

\begin{tabular}{|l|c|c|c|c|c|}
\hline Drug & Conc. $\mathrm{mg} / \mathrm{ml}$ & Bs. & Sa. & Ec. & Ps. \\
\hline Ampicillin & 40 & 15 & 30 & - & - \\
& 20 & 14 & 25 & - & - \\
& 10 & 11 & 15 & - & - \\
\hline Gentamycin & 40 & 25 & 19 & 22 & 21 \\
& 20 & 22 & 18 & 18 & 15 \\
& 10 & 17 & 14 & 15 & 12 \\
\hline
\end{tabular}

Table 7 : Antifungal activity of standard chemotherapeutic agents against standard fungi

\begin{tabular}{|l|c|c|c|}
\hline Drug & Conc. $\mathrm{mg} / \mathrm{ml}$ & An. & Ca. \\
\hline Clotrimazole & 30 & 22 & 38 \\
& 15 & 17 & 31 \\
& 7.5 & 16 & 29 \\
\hline
\end{tabular}

\footnotetext{
- Sa.: Staphylococcus aureus

* Ec.: Escherichia coli

* Pa.: Pseudomonas aeruginosa

* An.: Aspergillus niger

* Ca.: Candida albicans

* Bs.: Bacillus subtilis
}

The oil showed activity against all test organisms, but it was more active against the fungus Aspergillus niger and the bacterial strain Staphylococcus aureus .

\section{References:-}

1. Ambasta S.P.(2004) : The Useful Plants of India, 4th ed. ,National Institute of Science Communication , New Delhi , pp. 94-5.

2. Ahsan R., Islam, M.(2009a), Euro J Sci Res. ,41,227-32.

3. Ahsan, R., Islam, M.(2009b), Euro. J. Sci. Res.,37,302-10.

4. David, G.(2014), Chemical Science Transactions,3 (3), 1127.

5. Duke JA. (2004) : Handbook of Legumes of World Economic Importance, Plenum Press, NewYork, pp. 33-7.

6. Jaiswal, D., Rai, P.K., Kumar, A., Watal, G.(2008), Indian J. Clin. Biochem., 23,167-70.

7. Luo, M., Liu,. X, Zu, Y., Fu, Y., Zhang, S., Yao, L.(2010) ,Chem. Biol. Interac., 188,151-60.

8. Pal ,D.K., Mohapatra, T.K., Das ,A.(2008), Ancient Sci Life. ,17,41-4 .

9. Pal, D.K., Sahoo, M., Mishra, A.K. (2007), Asian J Chem.,19,793-5.

10. Rama, S., Mahtha, B., Archana P., Srikanth, K.(2013), Int. J. pharm.Sci. Rev. Res. ,22(1) ,11.

11. Salunkhe ,D.K., S.S.Kadam and Chavan, J.K.(1985), Post Harvest Biotechnology of Food Legumes, C.R.C press Inc. ,Boca Raton, Florida USA.

12. Singh, U., R. Jambunathan, K.B. Saxena and Subrahmanyam,N. (1990), J. Scs. Food Agric., 50, 201-209.

13. Singh S.K . ( 1977) : Food Legumes Distribution, Adaptapility and Biology of Yield, In.: Plant Production and Protection, paper 3. FAO. Rome, pp:102.

14. Singh, S., Mehta, A., John, J., Mehta, P.(2010), Pharmacog. J. ,2,71-3.

15. Van Den Beldt, R.J.( 1988) : Cajanus cajan, Tree Network (FACT Net), ICRISAT Sahelian center.

16. Van Der Maesen, L.G.J.(1986): Cajanus Dc and Alylosia (Leguminosaea ), Agriculture University of Wageningen paper, pp:85-94.

17. Yuan-gang Zu, Xiao-lei, Yu-jie Fu, Nan Wu, YuKong, Michael W. (2010), Phytomed. ,17,1095-101. 